\title{
Relações entre Liderança e Vínculos com a Organização: um estudo em um tribunal
}

Daniela Campos Bahia Moscon. Universidade Salvador

Antônio Virgílio Bittencourt Bastos. Universidade Federal da Bahia

\section{Resumo}

O objetivo desse estudo é analisar as relações entre a percepção dos empregados acerca dos estilos de Liderança Transformacional (TRANSF) e Transacional (TRANS) dos gestores de um tribunal com os vínculos de Entrincheiramento (EO), Consentimento (CONS) e Comprometimento (CO). Para coleta de dados foi aplicado (a 173 funcionários de um tribunal) um questionário composto de: a) percepção acerca de antecedentes dos vínculos com a organização; b) CO (Bastos \& Aguiar, 2008), EO (Rodrigues \& Bastos, 2012) e CONS (Silva \& Bastos, 2010); c) TRANF e, TRANS (Northouse, 2004); d) dados pessoais e ocupacionais. Observou-se que a liderança tem relações mais significativas com o CO e traz impactos no CONS, mas não o suficiente para explicá-lo, sendo a percepção do empregado sobre políticas de gestão, antecedentes mais significativos. Já EO, se desenvolve mais por avaliações acerca das vantagens de estar na organização em comparação com a percepção sobre o mercado.

Palavras-chave: comprometimento organizacional; entrincheiramento organizacional; consentimento organizacional; estilos de liderança.

\begin{abstract}
Relations between Leadership and Workplaces Bonds: A study in a court. The objective of this study is to analyze the relations between the employees' styles of Transformational Leadership (TRANF) and Transactional (TRANS) Leadership of the managers in a court with links of Entrenchment (OE), Consent (CONS) and Commitment (CO). For data collection was used a questionnaire (for 173 employees) composed of: a) the workers' perception about workplace bonds; b) OC (Bastos \& Aguiar, 2008), OE (Rodrigues \& Bastos, 2012) and CONS (Silva \& Bastos, 2010); c) TRANSF and TRANS (Northouse, 2004); d) personal and occupational data. The results show that leadership, mainly TRANSF, has more significance with $O C$ and brings impacts on the CONS, but it is not enough to explain it, and the perception of management policies is more significant. With regard to OE, develops more on account of evaluations that the employee does on the advantages of being in the organization compared to the market.
\end{abstract}

Keywords: organizational commitment; organizational entrenchment; consent organizational, leadership styles.

\section{Resumen}

Las relaciones entre liderazgo y vínculos con la organización : un estudio en un tribunal. El objetivo de este estudio es analizar las relaciones entre la percepción de los empleados acerca de los estilos de Liderazgo Transformacional (TRANSF) y Transaccional (TRANS) de los gestores de un tribunal con los vínculos de Atrincheramiento (AO), Consentimiento (CONS) y Compromiso (CO). Para la recolección de datos se utilizó un cuestionario (en 173 empleados) compuesto de: a) la percepción de los trabajadores acerca de diversos antecedentes de los vínculos con la organización; b) CO (Bastos \& Aguiar, 2008), AO (Rodrigues \& Bastos, 2012) y CONS (Silva \& Bastos, 2010); c) el TRANSF, TRANS y AO (Northouse, 2004); d) datos personales y ocupacionales. Los resultados apuntan que el liderazgo tiene relaciones más significativas con el CO y trae impactos importantes en el CONS, pero no es suficiente para explicarlo, siendo la percepción del empleado sobre políticas de gestión antecedentes más significativos. En lo que se refiere a la AO, se desarrolla más por cuenta de evaluaciones que el empleado hace de las ventajas de estar en la organización en comparación con lo que mercado. Palabras clave: compromiso de la organización; afianzamiento de la organización; el consentimiento de la organización; estilos de liderazgo. 
É notório que a compreensão de boa parte dos fenômenos que afetam o comportamento organizacional foi, prioritariamente, desenvolvida na esfera das organizações privadas, em especial, industriais. Sempre que tais fenômenos precisam ser utilizados para explicar os comportamentos nas organizações públicas requerem adaptações e novas formas de compreensão, em maior ou menor grau, tendo em vista que as peculiaridades desse contexto impedem a simples transposição dos modelos existentes.

Dentre os fenômenos estudados, a liderança se destaca em razão da ideia (algumas vezes até ingênua e exagerada) de que o líder é alguém capaz de levar a equipe a comportamentos desejáveis e metas de sucesso (Hackmans \& Wageman, 2007). Nesse sentido, enquanto no setor privado essa visão acerca das possibilidades do líder reveste-se de uma aura de otimismo, o oposto ocorre em relação à esfera pública. Wright e Pandey (2010) destacam que, apesar de não haver tantos estudos que testem ou adaptem os modelos de liderança existentes a esse tipo de contexto, frequentemente $o$ mainstream da área costuma ser pessimista em relação ao valor potencial da liderança na esfera pública.

Esse pessimismo é evidente especialmente quando se considera os modelos mais atuais utilizados para compreender o fenômeno. Dentre tais modelos, a teoria de Liderança Transformacional (TRANSF) e Transacional (TRANS) (Bass, 1999) tem se destacado como dominante nas pesquisas da área. Wright e Pandey (2010) destacam que, ao contrário do que ocorre na esfera privada, a TRANSF tem sido apontada como menos eficaz nas organizações públicas, em parte por conta do excesso de normas e da própria burocracia. Contrariamente a tais argumentos, metanálises têm consistentemente encontrado que tal estilo de liderança é, no mínimo, tão comum e eficaz nas organizações públicas, quanto nas privadas (Moynihan, Pandey \& Wright, 2014; Wright \& Pandey, 2010).

Dentre todos os efeitos positivos da liderança (nos seus mais diversos modelos explicativos) nas organizações, muita atenção tem sido dada à sua capacidade de facilitar nos empregados o estabelecimento de vínculos com a organização empregadora que promovam a sua adesão aos valores estabelecidos e os incentivem a se engajar em atividades extra papel. Dos vínculos estudados, o conceito de Comprometimento Organizacional (CO), por ser considerado mais operacionalizável em termos empíricos, tem recebido atenção especial nos últimos 20 anos (Bastos, Maia, Rodrigues, Macambira,
\& Borges-Andrade, 2014), quando se consolidou como campo profícuo de investigação para fins de resultados favoráveis para a organização e para o próprio sujeito.

Apesar da hegemonia que os estudos sobre $\mathrm{CO}$ alcançaram, não foi possível, ainda, obter consenso em relação ao significado do seu conceito (Bastos, Rodrigues, Moscon, Silva, \& Pinho, 2013; Klein, Cooper, Molloy, \& Swanson, 2014) que, na literatura do mainstream da área, adquire sentidos quase opostos, como permanecer na organização porque precisa dela (sugerindo um vínculo instrumental), porque sente-se obrigado (vínculo normativo) ou permanecer engajado e contributivo porque gosta da organização e se identifica com seus valores e sua missão (Meyer \& Allen, 1991). Análises teóricas e resultados de estudos empíricos têm apontado para o fato desse modelo (chamado modelo tridimensional) provocar redundância, imprecisão e alargamento excessivo do conceito de CO, que dificultam o avanço do conhecimento nessa área e contribuem pouco para uma melhor condução das pessoas nos ambientes de trabalho (Klein et al, 2014; Klein, Molloy, \& Brinsfield, 2012; Moscon, Bastos, \& Souza, 2012; Osigweh, 1989).

A tentativa de reduzir essas imprecisões motivou o desenvolvimento de uma linha de investigação que deu origem a alguns estudos no Brasil, partindo da proposição de novos conceitos que separem dimensões até então concebidas como parte do CO. Por essa proposta, a dimensão instrumental do CO seria abarcada pelo conceito de Entrincheiramento Organizacional (EO) (Rodrigues \& Bastos, 2011), definido como a tendência do indivíduo a permanecer na organização devido a possíveis perdas de investimentos e custos associados à sua saída e devido à percepção de poucas alternativas fora daquela organização. Já a dimensão normativa passaria a ser tratada a partir do conceito de Consentimento Organizacional (CONS) (Silva \& Bastos, 2010), apoiado em reflexões teóricas de conceitos correlatos, tais como 'conformismo' e 'obediência', no campo da Psicologia Social e da Sociologia.

Assim, por essa nova proposta, o conceito de CO se restringiria ao sentimento de orgulho por pertencer, o envolvimento com objetivos e valores e o empenho em favor de algo, retomando uma ideia clássica de unidimensionalidade que era comum nos estudos seminais do campo (Klein et al, 2014; Klein et al., 2012; Solinger, Van Olffen, \& Roe, 2008).

Vale destacar, entretanto, que se parece um fato a existência de relações entre liderança e o 
estabelecimento de vínculos por parte dos trabalhadores, observa-se que, conforme já destacado anteriormente, a amplitude desse impacto varia, em grande parte, em função da cultura e estrutura organizacional estabelecida e do contexto onde tais fenômenos ocorrem (Ortega-Parra \& Sastre-Castilho, 2013). É surpreendente, portanto, que poucas pesquisas tenham sido conduzidas no sentido de compreender como os modelos de Liderança TRANSF e TRANS se relacionam com o estabelecimento de vínculos de empregados em um contexto de organização pública. Esse estudo objetiva, portanto, analisar as relações entre a percepção dos empregados sobre os estilos TRANSF, TRANS e AO dos seus gestores com as dimensões dos seus vínculos de EO, CONS e CO no contexto do Tribunal Regional do Trabalho 5 (Bahia).

\section{Fundamentação teórica e proposição das hipóteses de pesquisa}

\section{Vínculos com a Organização}

Diversos são os conceitos relacionados na literatura para falar sobre os vínculos que o trabalhador desenvolve com o próprio trabalho e as organizações, tais como satisfação, envolvimento, apego, identificação, reciprocidade, suporte organizacional, percepção de justiça, dentre outros (Siqueira \& Gomide, 2014). Entretanto, desde a segunda metade do século XX, o conceito de $\mathrm{CO}$ tem dominado o interesse dos estudiosos da área, o que pode ser creditado, em grande medida, a evidências de seus efeitos na assiduidade, no turnover, na pontualidade, nos comportamentos de cidadania, na aceitação das mudanças e no desempenho dos membros organizacionais.

Apesar dos inegáveis avanços que a pesquisa nessa área já foi capaz de obter, ainda existem controvérsias em torno do conceito de $\mathrm{CO}$ e sugestões de refinamento vêm sendo propostas, em especial no que se refere a críticas realizadas ao modelo hegemônico no campo, que entende o comprometimento a partir de três bases distintas: afetiva, normativa e calculativa ou instrumental (Meyer \& Allen, 1991). Nessa direção, investigações realizadas por um grupo de pesquisadores brasileiros vem sustentando a ideia de que CO deve se restringir à sua base afetiva e a uma atitude mais ativa por parte do trabalhador (desejo de permanecer e contribuir), abandonando as vertentes classicamente a ele associadas de base instrumental e normativa.
No caso da base normativa, Silva e Bastos (2010) propõem que seja abarcada pelo conceito de CONS. Já a base instrumental, passaria a compor o constructo do EO (Rodrigues \& Bastos, 2011).

No que se refere ao CONS, é oriundo da literatura da Sociologia do Trabalho e se caracteriza por um tipo de vínculo do indivíduo pautado na internalização do papel de subordinação presente nas relações de trabalho, o que o leva a consentir ou a obedecer às normas e regras da organização, comumente proferidas pelo superior imediato. Análises teóricas e empíricas realizadas por Silva e Bastos (2010) revelaram que o CONS deve ser conceituado a partir de duas dimensões: 'Obediência Cega' e 'Aceitação Íntima'. Neste modelo, pressupõe-se que o trabalhador consente com as demandas organizacionais motivado por uma obediência ao superior, seja em função da sua posição de subordinado, por uma resposta automática (cega), ou em decorrência de Aceitação Íntima baseada na crença genuína dos valores e objetivos organizacionais.

A formalização da esfera pública pode, portanto, ser favorável ao estabelecimento do CONS, mas, apesar disso, o líder poderia estar de certo modo refém das normas e regras estabelecidas pelo próprio orgão (mais normativo que na esfera das organizações privadas) e com reduzido poder discricionário, especialmente no que tange à exigência do cumprimento de metas e à aplicação das sanções relacionadas a comportamentos indesejáveis no ambiente de trabalho.

Já o conceito de EO foi proposto por Rodrigues e Bastos (2011) com base nos estudos sobre comprometimento na carreira (Carson, Carson, \& Bedeian, 1995) como a tendência do indivíduo a permanecer na organização devido a possíveis perdas de investimentos e custos associados à sua saída, e devido à percepção de poucas alternativas fora daquela organização. Assim, o trabalhador pode permanecer por perceber a organização como uma trincheira, que dá uma ideia de uma forma de proteção ou garantia de seu status quo e evitação de outras perdas associadas à sua saída. Isso pode ocorrer, segundo Rodrigues e Bastos (2011), em razão de três motivos, que podem agir de modo isolado ou associado e podem, portanto, ser apontados como dimensões do próprio entrincheiramento.

A primeira dessas dimensões, intitulada Limitação de Alternativas (LA), se dá quando o empregado não visualiza outras oportunidades de emprego, seja em razão de perceber restrições de mercado, seja por entender que seu perfil profissional não seria 
aceito por outras organizações, devido a limitações de idade, conhecimento, entre outros. Já a segunda dimensão, chamada pela autora de Arranjos Burocráticos Impessoais ( $\mathrm{ABI}$ ), ocorre quando o empregado hesita perder ganhos financeiros, benefícios e estabilidade, remuneração variável, benefícios de assistência médica, aposentadoria, entre outros. A terceira e última dimensão, Ajustamento à Posição Social (APS), ocorre em razão da necessidade de preservar os ajustamentos que foram necessários para sua adaptação à realidade organizacional específica em que se encontra, tais quais desenvolvimento de habilidades voltadas para suas tarefas, rede de relacionamentos criada, entre outros.

\section{A Liderança Transacional e o Estabelecimento dos Vínculos}

A TRANS é aquela que, segundo Bass (1999), refere-se às trocas estabelecidas no relacionamento entre líder e seguidor cuja finalidade seja satisfazer os interesses de ambos. Para Gomes e Cruz (2007), baseia-se na legitimidade e autoridade formais, a partir da ênfase nas normas estabelecidas pelas instâncias superiores e a chamada de atenção para o cumprimento das tarefas previamente definidas, principalmente a partir da aplicação de reforços e punições. Ela tem sido estudada a partir de dois componentes. O primeiro desses componentes, Recompensa Contingente, é o que é baseado, de fato, no reforçamento constante por parte dos líderes dos comportamentos esperados pelos liderados. Dessa forma, ancora-se na ideia de que o relacionamento entre ambos se baseia na troca transacional de recompensas e reconhecimento de realizações para os resultados desejados (Bass, 1999). O segundo componente, chamado de Gerência pela Exceção, trata do relacionamento em que o feedback ao liderado se dá apenas quando ocorre um erro ou um problema, que pode ocorrer de forma ativa ou passiva (Bycio, Hackett, \& Allen, 1995).

A Recompensa Contingente tem sido altamente correlacionada com a TRANSF (Avolio, Bass, \& Jung, 1999), já que também traz impactos positivos nos resultados dos subordinados, tais como satisfação e desempenho, embora em menor extensão. Já a Gestão Ativa por Exceção é plausivelmente mais eficaz do que o gerenciamento passivo. Isso ocorre porque as críticas do líder se forem justas e construtivas, podem evitar consequências aversivas e ajudar a modificar o mau desempenho.

Ainda tratando da TRANS e tentando compreendê-la de forma específica em organizações públicas, é necessário se atentar para o fato de que o uso limitado de medição de desempenho é uma questão fundamental nessa realidade. A gestão pública é normalmente vista como um contexto ambíguo, onde predomina uma dificuldade de medir as metas de desempenho, bem como as recompensas extrínsecas relacionadas a elas. Segundo Hooijberg e Choi (2001) tal dificuldade pode ser resultante de não haver um foco tão mensurável quanto na esfera privada (nesse caso o lucro) e os funcionários serem "protegidos", na maior parte das vezes, pela estabilidade no emprego. Esses fatores fazem com que a distribuição de recompensas e méritos extrínsecos estejam muito mais associados à senioridade e tempo de serviço, do que a desempenhos diferenciados (Schikmann, 2010).

Hooijberg e Choi (2001) destacam que diferentemente do setor privado, onde as regras servem para dizer ao empregado o que ele não deve fazer, no contexto público, em geral, elas dizem o que eles devem fazer. Para Ckagnazaroff (2002), o funcionário público é orientado pelas noções de responsabilidade e dever, onde a autoridade depende de regras fixas e da implementação de acordos com procedimentos já estabelecidos. Isso significa que o poder discricionário na administração pública é limitado e que os líderes e empregados acabam se preocupando mais com a obediência a regras impostas. Apesar disso, as sanções ao descumprimento costumam ser muito mais brandas na esfera pública, especialmente em razão da estabilidade no emprego da qual goza. Isso reforça a ideia de que a Recompensa Contingente esteja menos disponível nessa realidade do que a Gerência pela Exceção.

Vale destacar que, embora os argumentos supracitados possam sugerir que maiores escores na TRANS se relacionem com estabelecimento de vínculos instrumentais nas equipes de trabalho, é preciso destacar, entretanto, que no que se refere ao EO, as dimensões estabelecidas dependem mais da estrutura organizacional (ABI) e da análise do mercado de trabalho (LA) do que da ação do líder imediato. Assim, um empregado de um órgão público, que goza de certos privilégios relacionados à carga de trabalho, salário e, especialmente, estabilidade no emprego, pode não perceber alternativas melhores de trabalho fora dessa realidade e recear que, no caso de uma saída, possa perder os ganhos que tal arranjo lhe concede. Sendo assim, é possível que se observe altos escores de EO (Grillo-Rodrigues \& Bastos, 2013), mas pouca relação disso com o estilo de liderança mais ou menos transacional.

\section{A Liderança Transformacional e o Estabelecimento dos Vínculos}

Já na TRANSF, segundo Gomes e Cruz (2007), os processos de motivação são ancorados em apelo a 
valores morais, ideais que sejam superiores aos interesses individuais e formulação de uma determinada visão para a organização que é vista como merecedora de confiança e apoio. A TRANSF trata, portanto, da influência do líder sobre os liderados no sentido de transformar seus valores e prioridades enquanto os motivam a realizar um trabalho de melhor desempenho (Moynihan et al., 2014; Pierro, Raven, Amato, \& Bélanger, 2013). Por conta disso, os autores destacam que as pesquisas têm demonstrado efeitos desse tipo de liderança com fenômenos positivos no trabalho, tais como satisfação, coesão grupal e performance, dentre outros, especialmente o CO organizacional afetivo.

Segundo Bass (1999), existem quatro dimensões que caracterizam a TRANSF. A primeira delas, considerada o nível mais elevado, é chamada de Carisma ou Influência Idealizada e trata da liderança baseada em um modelo que desperte admiração, respeito e confiança. No segundo componente, Motivação Inspiracional, a preocupação é avaliar o quanto os líderes são capazes de fornecer aos seguidores um senso de propósito e energia para promover a realização de objetivos da organização. Nesse caso, eles costumam obter adesão dos seguidores em razão do uso de símbolos ou apelos emocionais, que, por conta disso, exercem esforços para o alcance dos resultados organizacionais. Já a Estimulação Intelectual pressupõe que os líderes estimulem seus seguidores a serem inovadores e questionarem as formas habituais de realizar o trabalho, visando descobrir novas formas de resolver os possíveis problemas existentes. Nesse caso, o líder incentiva os empregados a olhar para seu trabalho de maneiras diferentes e pensar "fora da caixa", proporcionando a oportunidade para a autonomia da tarefa, variedade e desafio adicional (Whittington et al, 2004). Por fim, o quarto fator é denominado Consideração Individualizada e é representada por líderes que se centram na compreensão das necessidades de cada seguidor e trabalham continuamente para levá-los a desenvolver seu pleno potencial (Avolio et al, 1999; Bass, 1999; Bycio et al, 1995; Gomes e Cruz, 2007; Pierro et. al., 2012).

No caso da administração pública, pode-se argumentar que, na inexistência de metas claramente estabelecidas e de recompensas a elas associadas, a presença da TRANSF seria ainda mais exigida, em razão da sua capacidade de fazer com que o seguidor transcenda essas expectativas mais imediatas e individuais e foque no atingimento de missões de maior alcance social (Wright \& Pandey, 2010). Os autores afirmam ainda que metanálises têm consistentemente encontrado que o comportamento de TRANSF é, no mínimo, tão comum e eficaz nas organizações públicas quanto nas privadas. Apesar disso, frequentemente, o mainstream da área costuma ser pessimista em relação ao valor potencial e à frequência com que essa dimensão da liderança se apresenta nas organizações públicas, em parte por conta do excesso de normas e da própria burocracia, conforme já discutido anteriormente.

Para Hooijberg e Choi (2001), as estruturas muito formalizadas reduzem a necessidade e o potencial da TRANSF, já que funcionariam, de certa forma, para os liderados, como espécies de seus substitutos. Primeiro, elas reduzem a necessidade de liderança usando os recursos organizacionais para fornecer regras suficientes para orientar o comportamento dos funcionários. Segundo, elas também reduzem o potencial para exercer a liderança, restringindo a capacidade do líder para agir de maneiras novas ou fornecer uma visão atraente, reinterpretando objetivos organizacionais em maneiras que são mais congruentes com os valores dos empregados.

Em uma meta-análise, Judge e Piccolo (2004) mostraram que o líder que demonstre Consideração Individualizada com seus empregados afeta os sentimentos de aceitação como membro da organização e, consequentemente, o CO, uma vez que ele é altamente associado com sentimentos de identificação e pertencimento (Meyer \& Allen, 1991). Outra dimensão que pode influenciar o CO dos funcionários é Carisma, na medida em que permite maior aceitação e incorporação de objetivos ideológicos relacionados com a missão da organização. Esses líderes geralmente fornecem uma visão de atraente futuro para os subordinados, o que pode dar mais significado ao seu trabalho e trazer-lhe inspiração e entusiasmo.

No que diz respeito ao CONS, o modo como o líder conduz a equipe no dia a dia do trabalho pode influenciar de modo significativo na compreensão da missão da organização, de modo a contribuir para que o empregado obedeça de forma cega ou as aceite como sendo parte de sua própria missão na organização. Vale destacar, inclusive, que duas das dimensões da TRANSF (Influência Idealizada e Motivação Inspiracional) tratam da capacidade do líder de fazer com que os empregados transcendam seus próprios interesses em favor de interesses coletivos ou organizacionais, características da dimensão Aceitação Íntima. Por outro lado, a Estimulação Intelectual deve desincentivar qualquer forma de obediência, no momento em que estimula a inovação e o questionamento da forma de desenvolver 
as atividades de trabalho. Sendo assim, ao considerarmos os arranjos burocráticos característicos da administração pública, é esperado que essa dimensão seja menos característica nesse contexto. Por fim, no caso da Consideração Individualizada, é possível que sua aplicação seja dificultada na administração pública, em razão da alta exigência de cumprimento de legislações, regras e normas estabelecidas, que dificultam a flexibilidade no que se refere ao relacionamento entre líder e liderado nos ambientes de trabalho.

\section{Proposição das hipóteses}

Considerando as discussões teóricas apresentadas, o presente estudo propõe as seguintes hipóteses acerca dos resultados a serem obtidos: (1) H1. O estilo de liderança adotado no TRT5 não explica a presença de CONS entre seus funcionários, (2) H2. Os índices de EO no TRT5 não se relacionam com o estilo de liderança percebido em relação aos seus gestores, (3) H3. A percepção dos funcionários do TRT 5 acerca da Liderança Transformacional dos seus gestores é a variável que melhor explica seu grau de $\mathrm{CO},(4) \mathrm{H} 4$. Os escores de CONS dos funcionários do TRT 5 apresentam correlações positivas com as dimensões Carisma e Motivação Inspiracional e negativas com Estimulação Intelectual.

\section{Método}

\section{Participantes}

Participaram da pesquisa funcionários públicos do TRT - 5, lotados em Varas do Trabalho e em setores administrativos em Salvador (Bahia) e região metropolitana. Foram entregues questionários em todas as varas do trabalho (um para cada empregado lá lotado) e nos setores administrativos com mais de oito funcionários, totalizando 500 questionários entregues. Apesar disso, tendo em vista que a participação do funcionário era voluntária, apenas 173 preencheram o questionário completo.

No que se refere à amostra investigada, observa-se que há um número um pouco maior de mulheres na amostra (53,4\%). Quanto à idade, a distribuição foi bastante homogênea entre as faixas, com exceção para os jovens de até 25 anos que aparecem em menor número (4,6\%). Chama a atenção na amostra o grau de escolaridade dos respondentes, já que $53,1 \%$ é pós-graduado e $92 \%$ têm pelo menos o nível superior completo e a renda, com 56,3\% com salário entre 11 e 20 salários mínimos. Além disso, 57\% têm menos de
10 anos na organização, mas, $20 \%$ têm entre 16 e 20 anos. A amostra foi composta prioritariamente $(76,8 \%)$ por funcionários que atuam na área judiciária (principalmente nas varas do trabalho) e que não possuem funções comissionadas ou de liderança $(74,6 \%)$.

\section{Instrumento}

Para coleta de dados foi utilizado um questionário de itens fechados para avaliar as variáveis-critério da pesquisa. A estrutura geral do questionário aplicado envolve quatro partes, todas com escala tipo likert de 6 (seis) pontos que variam de 1 (Discordo Totalmente) a 6 (Concordo Totalmente):

Parte I - Percepção do Contexto e das Políticas Organizacionais. Dividida em blocos formados por conjuntos de itens que avaliam como o trabalhador percebe as políticas organizacionais de gestão de pessoas (treinamento, remuneração e promoção) implementadas pela organização (alfa de Cronbach $=0,72$ ), além do suporte organizacional (alfa de Cronbach $=0,86$ ), pressões no trabalho (alpha de Cronbach $=0,7$ ) e percepção do mercado de trabalho e empregabilidade (alfa de Cronbach $=0,62$ ). Essa escala foi desenvolvida por um grupo de pesquisadores da Universidade Federal da Bahia baseada nos modelos de antecedentes de vínculos com a organização, passou por validação de juízes (pesquisadores da área) e, testada nesse estudo, obteve resultados consistentes no que se refere aos alfas de Cronbach, conforme apontado.

Parte II - Relação do Trabalhador com a Organização. Trabalhou-se com as seguintes escalas que passaram pelo processo de validação utilizando-se análises fatoriais exploratórias e confirmatórias: a) CO validada por Bastos e Aguiar (2008) que aperfeiçoou a medida das três bases propostas por Meyer e Allen (1991) mantendo exclusivamente o enfoque afetivo (10 itens, alpha de Cronbach =0,89); b) EO, validada por Rodrigues e Bastos (2012), integrada por três fatores: ajustamentos à posição social (oito itens, alpha de Cronbach = 0,80); Limitação de Alternativas (oito itens, alpha de Cronbach $=0,79$ ) e Arranjos Burocráticos Impessoais (oito itens, alpha de Cronbach =0,77); c) CONS, validada por Silva e Bastos (2010), integrada por dois fatores: Obediência Cega (11 itens, alpha de Cronbach $=0,87$ ) e Aceitação Íntima (6 itens, alpha de Cronbach =0,82).

Parte III - Avaliação da Liderança. Escala do MLQ (Multifactor, Leardership Questionnaire Form 6S), proposto por Bass e Avolio, 1992 (citado por Northouse, 2004), que é composto por 21 indicadores de liderança divididos em sete fatores, sendo dois transacionais 
(Recompensa Contingente e Gerenciamento pela Exceção), com alfa de Cronbach $=0,52$, quatro transformacionais (Carisma ou Influência Idealizada, Motivação Inspiracional, Estimulação Intelectual e Consideração Individualizada), com alfa de Cronbach $=0,95$, e um fator denominado ausência de liderança. A escala original passou por um processo de tradução, retrotradução e adaptação, já que o instrumento original foi proposto para a auto avaliação do líder e suas questões foram apresentadas aos liderados para avaliação da sua chefia;

Parte IV - Dados Pessoais e Oupacionais. Inclui dados sobre sexo, idade, formação escolar, grau de responsabilidade financeira sobre a família, etc.

\section{Procedimentos:}

$O$ instrumento de pesquisa foi aplicado em trabalhadores do TRT 5a Região (Salvador e região metropolitana) de diversos níveis e com diferentes atribuições funcionais, por meio de auto aplicação em versão impressa. Foram realizadas visitas aos locais de trabalho dos respondentes para entrega do questionário e nova visita (após prazo acordado entre as partes) para seu recolhimento.

Para o tratamento dos dados, foram realizadas análises de correlações de Pearson e regressões, com o auxílio do programa SPSS (v.23). As análises de correlação permitem verificar se existe ou não relacionamento entre as variáveis, assim como a direção desse relacionamento (positivo, negativo ou zero) e a sua magnitude (coeficiente de correlação). Com base nos resultados obtidos, foram conduzidas análises de regressão linear (método Enter), que visaram estabelecer um modelo de relacionamento entre as variáveis estudadas.

\section{Resultados e discussões}

Foram analisados os graus de correlação entre as dimensões e sub dimensões de Liderança com os três vínculos e suas sub dimensões (Tabela 1).

Tabela 1. Índices de Correlação entre Liderança e Vínculos na Organização

\begin{tabular}{|c|c|c|c|c|c|c|c|c|c|c|c|c|c|c|c|c|}
\hline & 1 & 2 & 3 & 4 & 5 & 6 & 7 & 8 & 9 & 10 & 11 & 12 & 13 & 14 & 15 & 16 \\
\hline \multicolumn{17}{|l|}{ 1. Comprometimento } \\
\hline 2. Consentimento &, $466^{* *}$ & & & & & & & & & & & & & & & \\
\hline \multicolumn{17}{|l|}{ 4. Obediência cega } \\
\hline 5. Entrincheiramento &, $235^{* *}$ &, $485^{* *}$ & & & & & & & & & & & & & & \\
\hline \multicolumn{17}{|l|}{$\begin{array}{l}\text { 7. Arranjos burocráticos } \\
\text { impessoais }\end{array}$} \\
\hline \multicolumn{17}{|l|}{ 8. Limitação de alternativas } \\
\hline $\begin{array}{l}\text { 9. Liderança } \\
\text { Transformacional }\end{array}$ &, $313^{* *}$ &, $307^{* *}$ &, $296^{* *}$ &, $264^{* *}$ & ,109 &, $185^{*}$ & ,012 &, 068 & & & & & & & & \\
\hline 12. Estimulação Intelectual &, $273^{* *}$ &, $338^{* *}$ &, $302^{* *}$ &, $293^{* *}$ & ,142 &, $185^{*}$ & ,032 & , 130 &, $945^{* *}$ &, $808^{* *}$ &, $886^{* *}$ & & & & & \\
\hline $\begin{array}{l}\text { 13. Consideração } \\
\text { Individualizada }\end{array}$ &, $260^{* *}$ &, $263^{* *}$ &, $246^{* *}$ &, $219^{* *}$ &, 036 &, $160^{*}$ &,- 043 &,- 032 &, $907^{* *}$ &, $779^{* *}$ &, $791^{* *}$ &, $810^{* *}$ & & & & \\
\hline 14. Liderança Transacional &, $274^{* *}$ &, $317^{* *}$ &, $317^{* *}$ &, $274^{* *}$ & ,116 &, $166^{*}$ & ,042 & ,074 &, $852^{* *}$ &, $775^{* *}$ &, $785^{* *}$ &, $804^{* *}$ &, $808^{* *}$ & & & \\
\hline $\begin{array}{l}\text { 15. Recompensa } \\
\text { Contingente }\end{array}$ &, $227^{* *}$ &, $310^{* *}$ &, $277^{* *}$ &, $301^{* *}$ & ,049 & ,134 &,- 013 &,- 004 & ,622** &, $593^{* *}$ &, $558^{* *}$ &, $592^{* *}$ &, $572^{* *}$ &, $842^{* *}$ & & \\
\hline 16. Gerência pela Exceção &, $257^{* *}$ &, $260^{* *}$ &, $286^{* *}$ &, $201^{* *}$ & ,178* & ,170* & ,102 &, $163^{*}$ &, $852^{* *}$ &, $751^{* *}$ &, $795^{* *}$ &, $800^{* *}$ &, $823^{* *}$ &, $920^{* *}$ &, $565^{* *}$ & \\
\hline 17. Ausência de Liderança &, 023 & ,128 &,- 011 &, $168^{*}$ &, $314^{* *}$ &, $312^{* *}$ & ,100 &, $358^{* *}$ &,- 002 & ,007 & ,019 &,- 012 &,- 019 & ,076 &,- 045 &, $221^{* *}$ \\
\hline
\end{tabular}

Nota. ${ }^{*} p<.001 ;{ }^{* *} p<.05$

No que se refere ao CO, observa-se alto grau de correlação com a TRANSF (relacionada com a H3). Entretanto, vale destacar que o grau de correlação observado na dimensão Carisma foi mais expressivo que na dimensão Estimulação Intelectual, chamando a atenção menor participação do caráter mais ativo do 
conceito de $\mathrm{CO}$, com o qual o componente Estimulação Intelectual se relaciona de modo mais claro. É possível que isso tenha ocorrido em função de se tratar de um órgão público, onde a predominância de regras, normas e legislações a serem cumpridas dificulte a ação do líder no sentido de incentivar a iniciativa e a criação de ideias novas para a realização das tarefas propostas. Esse mesmo argumento pode ser proposto para entender os índices mais baixos de correlação na sub dimensão Consideração Individualizada, que exige suporte e tratamentos particularizados, difíceis de serem implementados em contextos onde normas determinam tratamentos isonômicos de acordo com as regras estabelecidas.

Já o CONS, mostrou maior correlação com a TRANS, mas com resultados muito próximos da TRANSF. Entretanto, chama a atenção que justamente Estimulação Intelectual, tenha apresentado os índices de correlação mais altos, contrariando o que foi proposto na H4. Possivelmente, ao perceber que seu líder o estimula a encontrar novas alternativas para a resolução de problemas, o funcionário se sinta mais confiante para aceitar suas determinações e consentir com as regras estabelecidas. Tal inferência carece de investigação mais aprofundada em estudos posteriores, já que não se sustenta em estudos anteriores e nem na própria teoria sobre Consentimento Organizacional.
No que se refere ao EO, correlacionou-se de forma significativa apenas à $\mathrm{AO}$. Já era esperado que não se correlacionasse com Liderança (confirmando a H2), já que diz respeito muito mais a uma avaliação da estrutura organizacional, do mercado e das suas próprias capacitações frente a esse mercado. Vale destacar, inclusive, que das três dimensões de EO, foi justamente a que se refere ao Ajustamento à Posição Social (já que cabe também ao líder oferecer ambiente favorável ao melhor ajustamento do sujeito ao contexto organizacional) a que apresentou maiores correlações com a Liderança, nesse caso, com a sub-dimensão Motivação Inspiracional.

Além de analisar os graus de correlações entre as variáveis, optou-se também por identificar os impactos de variáveis independentes (neste caso, percepção sobre políticas de gestão de pessoas utilizadas pela organização, percepção de suporte organizacional, percepção sobre a equipe de trabalho, pressões no trabalho, percepção acerca do mercado de trabalho e empregabilidade e percepção de pressões no trabalho, além das TRANSF, TRANS e AO) em um resultado (neste caso, os níveis de CO, CONS e EO), e nesse caso, uma ferramenta estatística adequada é a análise de regressão linear. De um modo geral, observou-se que esse conjunto de variáveis independentes testadas foram capazes de explicar $30,3 \%$ da variância do CO, 18,0\% do CONS e $23,4 \%$ do EO, conforme Tabela 2.

Tabela 2. Coeficientes B de Regressão - Percepção do Empregado sobre a Organização e a Liderança e Comprometimento, Consentimento e Entrincheiramento Organizacional

\begin{tabular}{|c|c|c|c|}
\hline \multirow{2}{*}{ Variáveis } & Comprometimento & Consentimento & Entrincheiramento \\
\hline & $\beta$ & $\beta$ & B \\
\hline Liderança Transformacional & ,270 & ,148 & ,117 \\
\hline Ausência de Liderança & 071 &, 113 & ,295 \\
\hline Percepção sobre as políticas de gestão de pessoas & ,214 & ,106 & 057 \\
\hline Percepção de pressões no trabalho & 044 & ,018 & ,111 \\
\hline Percepção de suporte organizacional & ,263 & 134 & 153 \\
\hline $\mathrm{R}^{2}$ & ,303 & ,180 &, 234 \\
\hline$\Delta \mathrm{R}^{2}$ & ,272 & 145, & ,201 \\
\hline
\end{tabular}

Nota. Variáveis dependentes: Comprometimento, Consentimento e Entrincheiramento.

A regressão aponta que $27 \%$ do CO é explicado apenas pela TRANSF. Isso confirma a $\mathrm{H} 3$ e corrobora com Wright e Pandey (2010) quando afirmam que, contrariamente às expectativas, metanálises têm consistentemente encontrado que o comportamento de TRANSF é, no mínimo, tão comum e eficaz nas organizações públicas quanto nas privadas e se relaciona com comportamentos positivos no trabalho. Além disso, a ênfase no sentido de missão, próprio da TRANSF faz com que ela seja especialmente útil em organizações públicas e/ou sem fins lucrativos, cujo serviço à comunidade é seu 
objetivo principal. Além disso, para Oliveira, Sant'anna e Vaz (2010), as lideranças do setor público devem lidar com maior multiplicidade de interesses, nem sempre formalmente explicitados, o que lhes requer um maior esforço no sentido de atribuição do sentido comum do trabalho para os liderados. Hooijberg e Choi (2001) destacam, inclusive, que os treinamentos de liderança no setor público deveriam focar muito mais no desenvolvimento das habilidades de suporte e orientação aos empregados do que nas de alcance de metas e resultados mensuráveis, mais aplicáveis ao setor privado.

Além disso, a segunda variável que melhor explicou CO foi Percepção de Suporte e é importante destacar o papel da liderança imediata no que se refere ao seu poder de influenciar a percepção de justiça e suporte organizacional. Segundo Meyer e Allen (1997, p. 46), as experiências de trabalho, vivenciadas cotidianamente, "comunicam que a organização dá suporte aos seus empregados, trata-os com justiça, e aumenta seu senso de importância pessoal e competência por meio da valorização de suas contribuições para a organização".

No caso de CONS, conforme previsto $\mathrm{H} 1$, existe um equilíbrio de forças entre as variáveis estudadas e, possivelmente, outras não estudadas, tais como as que se referem a exigências de cumprimento de regras e sistema de normas da administração pública, responsáveis por explicar as razões pelas quais o empregado se subordina e consente com as determinações impostas pela organização. Chama a atenção, entretanto, o baixo percentual obtido no item que trata da percepção de pressões no trabalho, sugerindo que, embora os trabalhadores se sintam pressionados a trabalhar mais em menos tempo (realidade relativamente nova na administração pública), não é o que o faz aderir às determinações estabelecidas pela organização, possivelmente em razão da estabilidade que goza na função.

Por fim, no que tange ao EO, de fato, a percepção de que estar na organização é vantajoso (15,3\% em percepção de suporte), aliado à avaliação de que o mercado de trabalho é menos atraente do que sua organização empregadora (31,2\%), explicam de forma importante o estabelecimento do EO. Apesar disso, Rodrigues e Bastos (2011) chamam a atenção para o fato de que o EO pode ou não vir acompanhado de um vínculo afetivo, ou seja, EO e CO não caminham, necessariamente, de forma isolada. Sendo assim, o alto grau de variância explicada da dimensão $A O$ em relação ao EO (o que não ocorreu em relação ao $\mathrm{CO}$ ) pode ajudar a diferenciar essas duas realidades. Logo, pode-se supor que $a$ indiferença do líder em relação à sua equipe possa explicar de forma importante o desenvolvimento do vínculo instrumental e da sensação de estar preso pelas contingências favoráveis que o contexto lhe oferece.

\section{Considerações finais}

Vínculos no trabalho e liderança são, certamente, fenômenos que despertam grande interesse, e ao mesmo tempo, grandes divergências conceituais. Apesar dos avanços obtidos, observa-se que boa parte dos estudos existentes que procuram relacionar essas variáveis tem origem nos modelos de gestão privada, cujas características e objetivos podem divergir, em muito, da realidade dos órgãos públicos brasileiros.

O presente artigo trouxe como contribuições à compreensão de tal relação, em primeiro lugar, a ampliação da investigação de conceitos novos como EO e CONS, que vêm contribuindo para o refinamento e o avanço do conhecimento sobre CO. De forma mais específica, compreender como essas relações se estabelecem em um órgão público traz novas nuances aos conceitos e auxiliam na consolidação da proposta em andamento. Isso fica mais claro quando se observa que, em relação às hipóteses apresentadas, elas foram apenas parcialmente confirmadas. Isso reforça a possibilidade da existência de peculiaridades próprias do contexto ora investigado e as mudanças pelas quais a administração pública brasileira vem passando nas últimas décadas.

Começando pelos achados relativos a CONS, conforme era possível supor, os dados demonstraram significativo impacto da participação ou não da liderança, mas não tanto do estilo adotado, confirmando H1. Observa-se, ainda, que a percepção do sujeito em relação a outras variáveis do contexto teve participação tão importante quanto a liderança na determinação desse grau de vínculo, como a percepção de que existem benefício e outras políticas de gestão de pessoas favoráveis de um lado, e de que o mercado de trabalho não oferece atrativos tão interessantes quanto os que são oferecidos pela organização empregadora de outro. De todos os achados relacionados a CONS, um deles chamou especial atenção. Trata-se do alto grau de correlação encontrado entre esse vínculo e a sub dimensão Estimulação Intelectual da TRANSF (o que diverge da H4). Isso chama especial atenção pelo fato de que um dos argumentos favoráveis ao desenvolvimento de estudos que tratem o CONS como um 
conceito separado do CO é o seu caráter mais passivo, de certo modo incongruente com uma relação onde o líder estimula os empregados a encontrar novas maneiras de agir e solucionar os problemas existentes. Estudos posteriores poderão ajudar a elucidar essa aparente incoerência dos dados obtidos nesse estudo.

No que se refere a EO, de fato trata-se de um vínculo que se desenvolve mais por conta de avaliações que o empregado faz das vantagens de estar na organização em comparação com o que imagina que o mercado lhe oferece, do que pelo relacionamento que ele estabelece com a sua liderança, confirmando também a H2. Por fim, no que tange ao $\mathrm{CO}$, o maior destaque pode ser atribuído aos seus altos índices em relação aos demais vínculos. Além dos argumentos supracitados, pode-se creditar esse fato, ainda, às mudanças pelas quais o serviço público não apenas brasileiro, mas também em outros países (Moynihan et al., 2014) vem passando nas últimas décadas, o que acaba tornando as atividades mais desafiadoras e aproximando os líderes das suas equipes de trabalho. Aliás, essa proximidade fica clara quando se avalia o alto grau de correlação obtida entre CO e TRANSF, em todas as suas dimensões, assim como o impacto em termos de variância explicada dessa última sobre o vínculo referido. Conforme H3, a TRANSF foi, de fato, a variável que melhor explicou o CO. Além disso, não se pode deixar de considerar a influência do líder como mediador da percepção do empregado em relação ao suporte, nem às políticas e práticas de gestão de pessoas adotadas pela organização.

Os achados apresentados contribuem a análise das peculiaridades de um órgão público brasileiro e revelam que, conforme já aponta a literatura e diferente do que imaginam alguns pesquisadores mais pessimistas, a TRANSF é, não só aplicável, como fundamental para compreender as razões pelas quais um trabalhador adere às normas e aos valores de sua organização empregadora.

Como perspectivas para pesquisas futuras, sugere-se novos estudos que possam relacionar os três vínculos com liderança a partir de abordagens metodológicas mais flexíveis e compreensivas (observação e entrevista em profundidade, por exemplo), em contextos de trabalho mais variados que permitam entender melhor essas relações e contribuam para um maior refinamento conceitual desses fenômenos, tão fundamentais no universo das organizações contemporâneas.

\section{Referências}

Avolio B. J., Bass, B. M., \& Jung, D. (1999). Re-examining the components of transformational and transactional leadership using the Multifactor
Leadership. Journal of Occupational and Organizational Psychology, 72(4), 441-462. doi:10.1348/096317999166789

Bass, B. (1999).Two decades of research and development in transformational leadership. European Journal of Work and Organizational Psychology, 8(1), 9-32. doi: 10.1080/135943299398410

Bastos, A.V.B., \& Aguiar, C.V.N. (2008). Comprometimento Organizacional: aprimorando a medida das bases afetiva, de continuação e normativa para o contexto de trabalho no Brasil. In XIII Conferência Internacional Avaliação Psicológica: formas e textos. Anais do XIII Conferência Internacional Avaliação Psicológica: formas e contextos. Braga, Portugal.

Bastos, A. V. B., Maia, L. G. M., Rodrigues, A. C.D. A., Macambira, M. O., \& Borges-Andrade, J. E. (2014). Vínculos dos indivíduos com a organização: análise da produção científica brasileira 2000-2010. Psicologia: Teoria e Pesquisa, 30(2), 153-162. doi: 10.1590/S0102-37722014000200004

Bastos, A. V. B., Rodrigues, A. C. A., Moscon, D. C. B., Silva, E. E., \& Pinho, A. P.(2013). Comprometimento no trabalho: fundamentos para a gestão de pessoas. In L. O. Borges \& L. Mourão (Orgs), $O$ trabalho e as organizações: intervenções a partir da Psicologia (pp. 280-309). Porto Alegre: Artmed.

Bycio, P., Hackett, R. D., \& Allen, J. S. (1995). Further assessments of Bass' conceptualization of transactional and transformational leadership. Journal of Applied Psychology, 80(4), 468-478. doi: 10.1037/0021-9010.80.4.468

Carson, K. D., Carson, P. P., \& Bedeian, A. G. (1995). Development and construct of a career entrenchment measure. Journal of Occupational and Organizational Psychology, 68(4), 301-320. doi: 10.1111/j.2044-8325.1995.tb00589.x

Ckagnazaroff, I. B. (2002). Reforma gerencial e o papel do gestor público: ator de mudança ou de resistência? Comunicação apresentada no VII Congreso Internacional del CLAD sobre la Reforma del Estado y de la Administración Pública. Lisboa, Portugal.

Gomes, A. R., \& Cruz, J. (2007). Abordagem carismática e transformacional: modelos conceptuais e contributos para o exercício da liderança. Psicologia USP, 18(3), 143-161. doi: 10.1590/S0103-65642007000300008

Grilo-Rodrigues, A. P., \& Bastos, A. (2013). Os vínculos de comprometimento e entrincheiramento presentes nas organizações públicas. Revista de Ciências da Administração, 15(36), 143-158. doi 10.5007/2175-8077.2013v15n36p143

Hackman, J. R., \& Wageman, R. (2007). Asking the right questions about leadership: Discussion and conclusions. American Psychologist, 62(1), 43-47. doi: 10.1037/0003-066X.62.1.43

Hooijberg, R., \& Choi, J. (2001). The impact of organizational characteristics on leadership effectiveness models: An examination of leadership in a private and a public sector organization. Administration \& Society, 33(4), 403-431. doi: 10.1177/0095399701334002

Judge, T. A., \& Piccolo, R. F. (2004). Transformational and transactional leadership: A Meta-Analytic Test of Their Relative Validity. Journal of Applied Psychology, 89(5), 755-768. doi: 10.1037/0021-9010.89.5.755

Klein, H. J., Cooper, J. T., Molloy, J. C., \& Swanson, J. A. (2014). The assessment of commitment: Advantages of a unidimensional, targetfree approach. Journal of Applied Psychology, 99(2), 222-238. doi: $10.1037 / a 0034751$

Klein, H. J., Molloy, J. C., \& Brinsfield, C. T. (2012). Reconceptualizing workplace commitment to redress a stretched construct: revisiting assumptions and removing confounds. Academy of Management Review, 37(1), 130-151. doi: 10.5465/amr.2010.0018 
Meyer, J. P., \& Allen, N. J. (1991). A three-component conceptualization of organizational commitment. Human Resource Management Review, 1(1), 61-89. doi: 10.1016/1053-4822(91)90011-Z

Meyer, J. P., \& Allen, N. J. (1997). Managing for commitment. In Commitment in the workplace: Theory, research and application. Advanced Topics in Organizational Behavior. Thousand Oaks, California: SAGE Publications. doi: 10.4135/9781452231556.n5

Moscon, D. C. B., Bastos, A. V. B., \& Souza, J. J. (2012). É possível integrar, em um mesmo conceito, os vínculos afetivo e instrumental? O olhar de gestores sobre o comprometimento com a organização. Organizações \& Sociedade, 19(61), 357-373. doi: 10.1590/S1984-92302012000200010

Moynihan, D. P, Pandey, S. K., \& Wright, B. E. (2014). Transformational leadership in the public sector: Empirical evidence of its effects. in Y. K. Dwivedi, M. A. Shareef, S. K.

Northouse, P. G. (2004). Leadership: theory and practice. Thousand Oaks: Sage Publications.

Pandey, \& V. Kumar (Orgs.), Public administration reformation: Market demand from public organizations (pp. 87-104). Nova lorque: Routledge/Taylor and Francis.

Oliveira, F. B., Sant'anna, A. S., \& Vaz, S. L. (2010). Liderança no contexto da nova administração pública: uma análise sob a perspectiva de gestores públicos de Minas Gerais e Rio de Janeiro. Revista de Administração Pública 44(6), 1453-1475. doi: 10.1590/S0034-76122010000600009

Ortega-Parra, A., \& Sastre-Castillo, M. A. (2013). Impact of perceived corporate culture on organizational commitment. Management Decision, 51(5), 1071-1083. doi: 10.1108/MD-08-2012-0599

Osigweh, C. (1989). Concept fallibility in organizational science. The Academy of Management Review, 14(4), 579-594. doi: $10.2307 / 258560$

Pierro, A., Raven, B. H., Amato, C., \& Bélanger, J. J. (2013). Bases of social power, leadership styles, and organizational commitment. International Journal of Psychology, 48(6), 1122-1134. doi: 10.1080/00207594.2012.733398
Rodrigues, A. C. A., \& Bastos, A. V. B. (2011). Entrincheiramento Organizacional: proposta de um novo vínculo indivíduo-organização. In J.C.Zanelli, N.Silva, \& S. R. Tolfo (Orgs.), Processos psicossociais nas organizações e no trabalho (pp. 161-178). São Paulo: Casa do Psicólogo.

Rodrigues, A. C. A., \& Bastos, A. V. B. (2012). Entrincheiramento Organizacional: construção e validação da escala. Psicologia: Reflexão e Crítica, 25(4), 688-700. doi: 10.1590/S0102-79722012000400008

Schikmann, R. (2010). Bases para a concepção do curso de especialização em gestão de pessoas no serviço público. In M. R. S. Camões, M. J. Pantoja, \& S. Bergue (Orgs), Gestão de pessoas: bases teóricas e experiências no setor público/organizado (pp. 9-28). Brasília: ENAP.

Silva, E. E., \& Bastos, A. V. B. (2010). A Escala de Consentimento Organizacional: construção e evidências de sua validade. Revista Psicologia: Organização e Trabalho, 10(1), 7-22. Recuperado de https://periodicos.ufsc.br/index.php/rpot/article/view/17273

Siqueira, M.M.; \& Gomide, S. (2014). Vínculos do indivíduo com o trabalho e com a organização. In J. C. Zanelli; J. E. Borges-Andrade; \& A. V. B. Bastos (Orgs.), Psicologia, organizações e trabalho no Brasil (2 ed., pp. 316-347). Porto Alegre: Artmed.

Solinger, O. N., Van Olffen, W., \& Roe, R. A. (2008). Beyond the threecomponent model of organizational commitment. Journal of Applied Psychology, 93(1), 70-83. doi: 10.1037/0021-9010.93.1.70

Scheible, A. C. F., \& Bastos, A. V. B. (2014). Analyzing the impacts of commitment and entrenchment on behavioral intentions. Universitas Psychologica, 13(1), 109-119. Recuperado de http://www.scielo.org.co/ scielo.php?script=sci_arttext\&pid=S1657-92672014000100010\&lng=p t\&tlng=en

Whittington, J. L., Goodwin, V. L., \& Murray, B. (2004). Transformational leadership, goal difficulty, and job design: Independent and interactive effects on employee outcomes. The Leadership Quarterly, 5(15), 593-606. doi:10.1016/j.leaqua.2004.07.001

Wright, B., \& Pandey, S. K. (2010). Transformational leadership in the public sector: Does structure matter? Journal of Public Administration Research and Theory; 20(1), 75-89. doi: 10.1093/jopart/mup003

Daniela Campos Bahia Moscon, Doutora em Administração pela Universidade Federal da Bahia - UFBA, é Professora do Programa de Pós-Graduação em Administração da Universidade Salvador UNIFACS. E-mails: danielamoscon@yahoo.com.br; danielacbahia@gmail.com; danielamoscon@yahoo.com.br

Antônio Virgilio Bittencourt Bastos, Doutor em Psicologia pela Universidade de Brasília - UnB, é Professor Titular do Instituto de Psicologia da Universidade Federal da Bahia - UFBA. E-mails: antoniovirgiliobastos@gmail.com; virgilio@ufba.br

Recebido em 01.jun.16 Revisado em 20.abr.19 Aceito em 03.jun.19 